\title{
Simulations of hot forming processes of variable thicknesses workpieces
}

\author{
Symulacje procesów tłoczenia na gorąco \\ wytłoczek o zmiennej grubości
}

IRENEUSZ WRÓBEL DAMIAN FIRGANEK *

\begin{abstract}
Methodology of production process analysis - by means of hot forming - using workpieces of variable thickness, was presented. Finite element simulations were performed using specialized software for the typical car body element - the longitudinal longeron. The simulation results were presented and discussed as well as conclusions and recommendations were formulated.
\end{abstract}

KEYWORDS: hot forming, FEM simulation, variable thickness draw pieces

The process of hot forming is heat-plastic treatment. It consists in forming a flat form heated to a temperature of austenization (approximately $930^{\circ} \mathrm{C}$ ), while hardening so formed draw piece. The entire process takes place in a specialized tool (die). This results in an draw piece with high mechanical properties: $R e$ yield strength from 1045 to $1100 \mathrm{MPa}$, strength limit $R \mathrm{~m}$ from 1450 to $1500 \mathrm{MPa}$ and hardness from 450 to $500 \mathrm{HV}$.

The body parts produced by the hot forming method can have much smaller mass and, at the same time, very good strength parameters. This allowed to reduce the weight of new generation cars of approximately $20 \%$ as compared to previous models.

An important advantage of hot forming technology is the lack of reciprocal spring phenomenon, which is a serious technical problem in the case of pressing of body parts from sheets with high durability parameters. Usibor 1500 and the new Usibor 2000 steels are used for hot forming. They are well tempered steels, which have a ferritic-perlite structure before heat treatment, while after thermal treatment - martensitic structure.

Hot forming method allows to produce draw pieces with variable rigidity. As a result, engineers can design special body crumple zones or places, where draw piece will be deformed (e.g. during accident). In this way, the newly designed vehicles meet higher safety requirements.

There are several methods of obtaining draw pieces with specified (variable) rigidity. One of these methods is the use of a form of varying thickness, which can be obtained by:

- $\quad$ use of metal sheet (supplied by the steelworks) with variable thickness - the sheet is rolled to obtain the required thickness in the respective region of the sheet (taylored rolled blank - TRB)) (fig. 1a),

- use of two or more strips of different thicknesses that are laser-welded to obtain a strip of variable thickness (taylored welded blank - TWB) (fig. 1b)

\footnotetext{
* Dr hab. inż. Ireneusz Wróbel (iwrobel@ath.bielsko.pl) - Akademia Techniczno-Humanistyczna w Bielsku-Białej; mgr inż. Damian Firganek (dfirganek@polmotors.com.pl) - Polmotors Sp. z o.o.
}

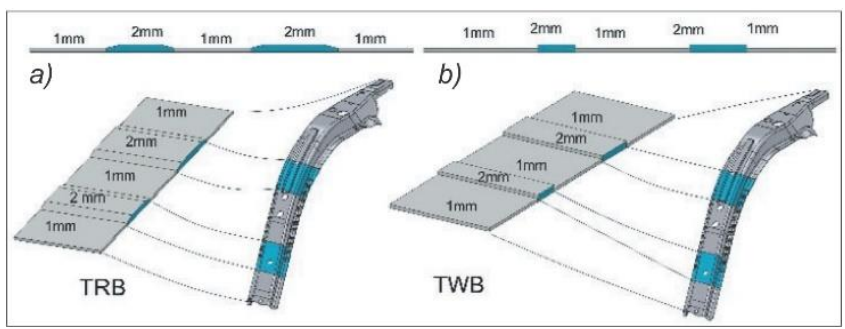

Fig. 1. Variable thickness sheets: $a$ ) rolled, $b$ ) laser welded (prepared by: I. Wróbel)

With such resulting strip, forms are cut, from which draw pieces with variable rigidity are produced.

Technological process of hot forming starts from the slice plane to size in the appropriate shape, which is an extension of a flat draw piece. The form is transferred to the furnace, where it is heated up to the austenization temperature $\left(920 \div 940^{\circ} \mathrm{C}\right)$, and then to the die mounted in the press. Subsequently, following closure of the stamp with the die and the contact pressure lasting for a few seconds $(3 \div 5 \mathrm{~s})$ occurs. At this time, the draw piece cools quickly and martensite transformation occurs. After cooling the draw piece to a temperature of approximately $150^{\circ} \mathrm{C}$, the die is opened and another manipulator supplies ready draw piece to a special conveyor belt. The next stage of production is the laser cutting of these edges or holes, which have a higher tolerance of execution. At the end, the draw piece is packaged and sent to the recipient. This process is schematically shown in fig. 2 .

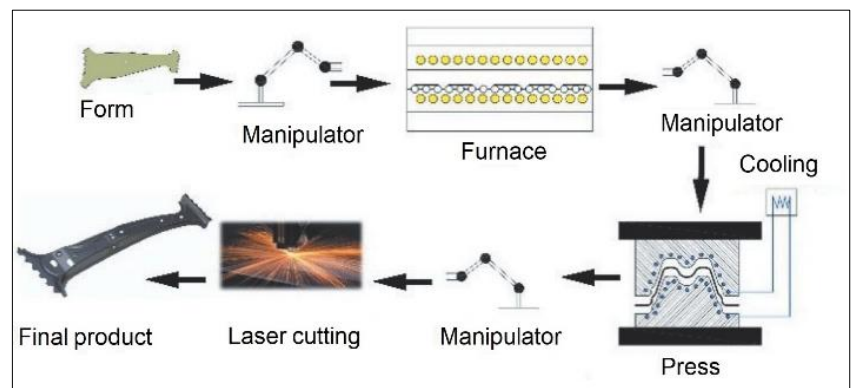

Fig. 2. Hot forming process (prepared by I. Wróbel)

\section{Purpose of analysis}

The extruding process of the variable-thickness draw piece should be designed so that the final product has no defects in the form of cracks or wrinkles; it is made with appropriate dimensional shape (as in cold extrusion), has the desired mechanical properties (strength and hardness) and metallographic structure (martensite). To meet these requirements, it is necessary to conduct a computer simulation of the designed process. 
The input in the process of hot forming are: form (with variable thicknesses in the respective regions), shape of the form, temperature of the form after leaving the furnace, time of transfer from the furnace to the die, forming time and tempering time, pressing force of the press quenching end temperature, extrusion speed of the elements in the die (punch, clamps). Computer analysis of the process of hot forming the draw pieces of variable thickness is carried out using specialized software such as Autofrom, PAmStamp or DynaForm. The software is based on a very popular finite element method. Diagram illustrating performing the analysis process of hot forming has been widely discussed in a publication [1]. This scheme can be successfully applied in the analysis process of hot forming the draw piece of variable thickness.

\section{Analysis of the hot forming process of the side longeron}

Fig. 3 shows the draw piece CAD model, for which a suitable hot forming process has been proposed. The die is composed of 3 elements (connected by a laser weld) of 2 different thicknesses: $1.4 \mathrm{~mm}$ and $2 \mathrm{~mm}$. The first step in the design of the extrusion manufacturing process is to carry out a feasibility study. This consists in determining the optimum direction of opening of the die and the analysis of the geometry of the stamp in terms of the possibility of its production by the pressing method.

Fig. 4 shows results of this analysis in the form of contours. Green color means that all angles measured with respect to the direction of opening of the die have correct values, yellow color indicates areas with cutoff values, and red color indicates that areas in the regions have to change the shape of the stamp. In the case of the analyzed part, the green contour occupied $100 \%$ of the extruded surface area.

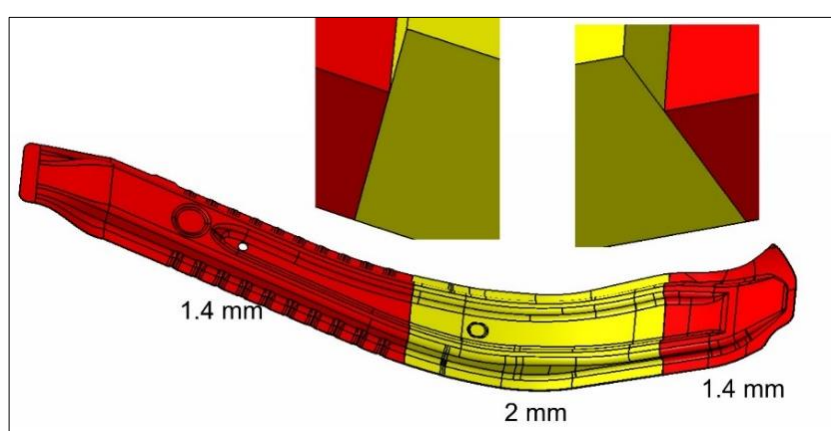

Fig. 3. CAD model of draw piece with variable thickness (prepared by l. Wróbel)

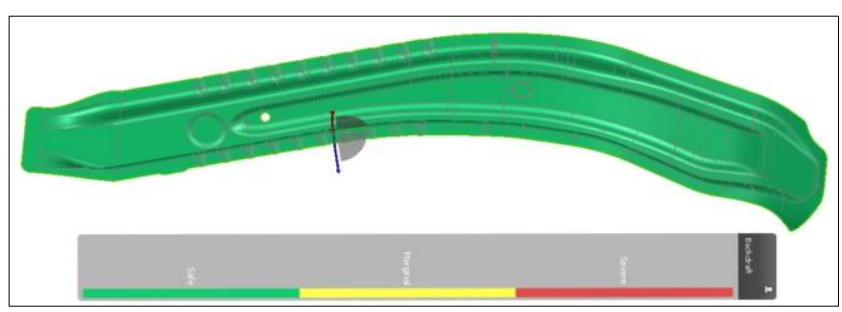

Fig. 4. Results of the draw piece geometry analysis in terms of feasibility (prepared by I. Wróbel)

In the next stage, guidelines for the process and the concept of tools were developed. In this case, it was assumed that the tool would consist of a stamp die and a press die, and the molding process would proceed in the following sequence: first, the pressure would close and align the form in the die, and then the mold would close with the die mold. Appropriate pressures were assumed between the pressure and the die and the punch and the die, as well as the corresponding distances between the tool elements. In order to prevent uncontrolled movement of the form during forming, referencing was scheduled to the form in the die of its contour by means of four pins based (i.e. pilots) and in the technological opening, which assumes a single based pin. For this concept of tools, CAD models of die, stamps, clamps and base pins were developed (fig. 5). Discrete models (FEM) were developed based on CAD tools. Elements of tools (die, stamp, pressure transmitters, and pilots) were modeled as rigid, and the form, which is compliant, was modeled with coating elements.

The next stage of the analysis of the hot forming process was to define the process parameters. These parameters can be divided into 3 groups:

- furnace parameters (temperature of the mold, soaking time) and transfer of the mold from the furnace to the die (furnace transfer time to the die and ambient temperature),

- parameters related to the pressing process (kinematics and pressure of the press),

- parameters of the quenching process (die stamping force, tempering time and end temperature of the stamp).

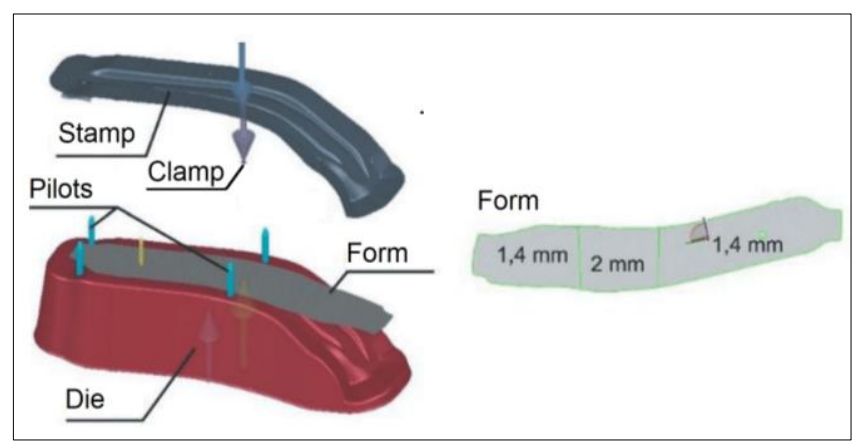

Fig. 5. Tool CAD models (prepared by I. Wróbel)

After defining the FEM models of tools and forms as well as kinematics, mechanical and thermal parameters of the process, the FEM analysis was performed using the Autoform solver.

\section{Results of analysis}

The basic results of the simulation, that are analyzed by the engineers, include:

- layers of the draw piece material thinning,

- so-called layers of FLD (forming limit diagram),

- layers with distribution of hardness and decomposition of martensite in the draw piece,

- temperature at key moments of the process,

- deformation of the draw piece at different stages of the forming process.

Fig. 6 shows layers of the draw piece thinning. It is assumed that for $22 \mathrm{MnB} 5$ material, maximum thinning should not exceed $18 \%$. In the present case, this condition was fulfilled.

Fig. 7 shows FLD layers that illustrate the behavior of material during the forming process. Based on the analysis of this diagram, it can be concluded that there are no areas where there is a risk of material breakage or excessive stretching. In most of the area (over $70 \%$ ), the material does not stretch or it extends in a safe range. The compressed area is approximately $27 \%$ of the draw piece 
surface area. In extreme cases, this can result in wrinkling, especially when the material thickening is greater than $15 \%$ (fig. 5 ).

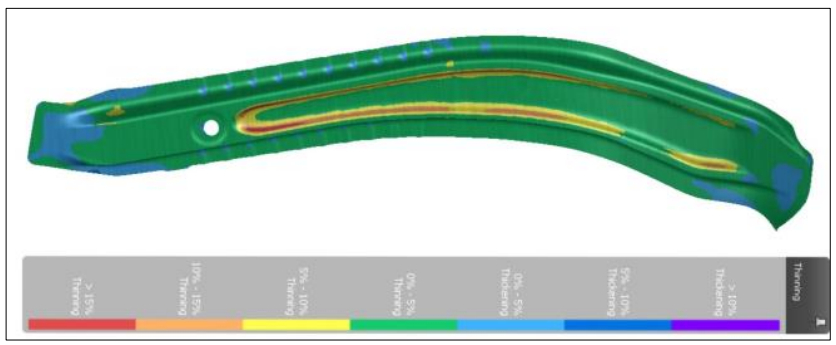

Fig. 6. Layers of the draw piece thinning (prepared by I. Wróbel)

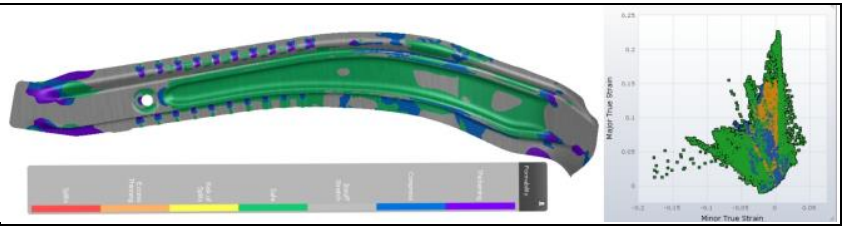

Fig. 7. FLD layers of the draw piece (prepared by I. Wróbel)

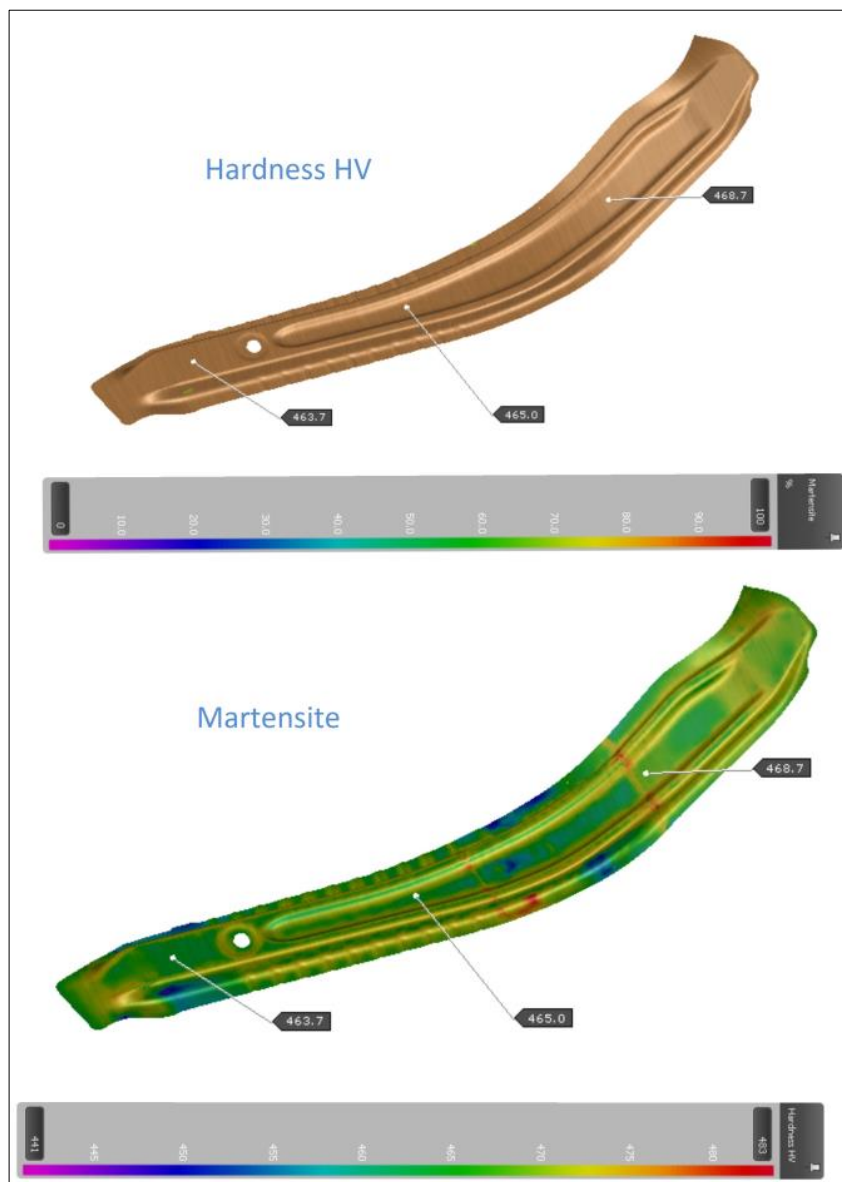

Fig. 8. Hardness and martensite layers (prepared by I. Wróbel)

TABLE. Temperature at key stages of the process

\begin{tabular}{|c|c|c|c|}
\hline $\begin{array}{c}\text { After } \\
\text { removal } \\
\text { from the } \\
\text { furnace }\end{array}$ & $\begin{array}{c}\text { After transferring } \\
\text { the draw piece to } \\
\text { the die }\end{array}$ & $\begin{array}{c}\text { Before } \\
\text { quenching }\end{array}$ & $\begin{array}{c}\text { Final draw } \\
\text { piece }\end{array}$ \\
\hline $930^{\circ} \mathrm{C}$ & $830^{\circ} \mathrm{C}$ & $740^{\circ} \mathrm{C}$ & $140^{\circ} \mathrm{C}$ \\
\hline
\end{tabular}

Important results of the simulation process of hot forming are contour lines depicting the percentage of martensite formed during quenching and hardness, to which the draw piece was quenched (these layers are shown in fig. 8), and further: temperature of the form and draw piece at key stages of the process - after removal from the furnace, after moving the draw piece from furnace to the die, before the tempering process, and after forming and hardening processes (table). Analyzing data presented in the table, it can be concluded that the temperature at each stage of the process is correct and the whole process will have the correct course.

The forming process depends on the spacing of the die from the stamp, as shown in fig. 9. It is possible to see that at some stage of forming, there is not much tendency to form wrinkles, which can then be crushed. There is no such danger in the analyzed case.

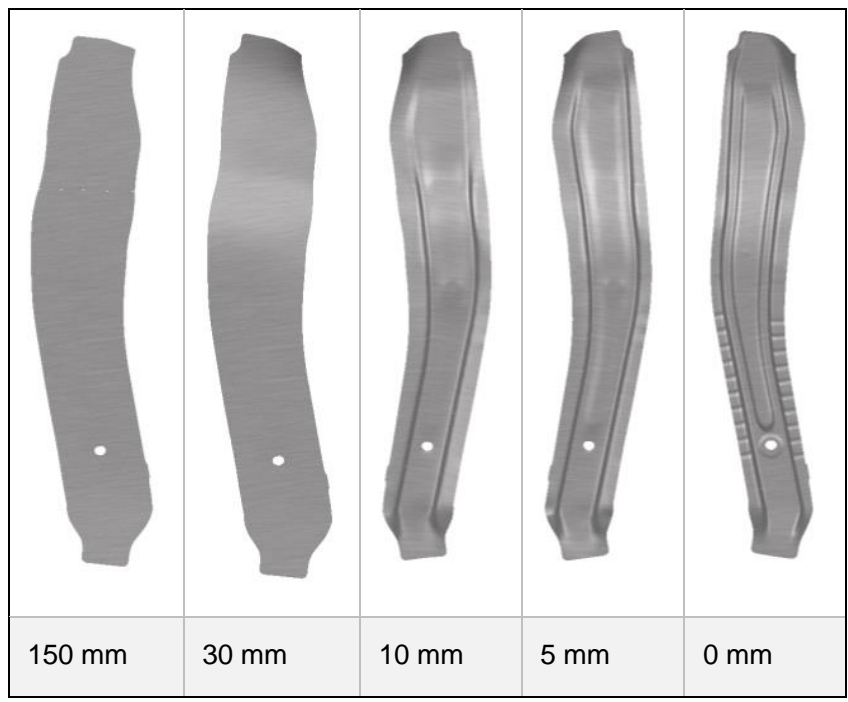

Fig. 9. Process of forming the draw piece according to distance of stamp from die (prepared by I. Wróbel)

\section{Conclusions}

The use of computerized FEM systems for the analysis of manufacturing processes allows for the verification of technical and technological assumptions for the complex process of hot forming the draw pieces with variable thickness. This analysis should take into account factors related to plastic and thermal processing. Using CAx tools, correctness of such process can be designed and validated.

The process proposed in this paper has been verified in industrial practice.

\section{REFERENCES}

1. Wróbel I. „Symulacja MES procesów tłoczenia na gorąco”. XXI Międzynarodowa Szkoła Komputerowego Wspomagania Projektowania, Wytwarzania i Eksploatacji, Jurata, 2017.

2. Erhardt R., Böke J. "Industrial application of hot forming press simulation". 1st International Conference on Hot Sheet Metal Forming of High-Performance Steel. Kassel, Germany, 2008.

3. Minjung K., Young-Min K., Cheolhee K. "Effect of heating parameters on laser welded tailored blanks of hot press forming steel". Journal of Materials Processing Technology. 228 (2016): pages 137-144.

4. Choi J.W., Lee M.G., Barlat F., Son H.S., Nam J.B. "Hot press forming of tailor welded blank: experiments and FE modeling". ISIJ, 2012.

5. Merkleina M., Wielanda M., Lechnera M., Bruschib S., Ghiottib A. "Hot stamping of boron steel sheets with tailored properties". Journal of Materials Processing Technology. 228 (2016): pages 11-24.

6 . Mori K., Okuda Y. "Tailor die quenching in hot stamping for producing ultra-high strength steel formed parts having strength distribution". CIRP Annals - Manufacturing Technology. 59 (2010): pages 291-294.

7. Autoform help and tutorial. 